\title{
Intensity Dependent Photoconductivity in ZnO Nanostructured Film
}

\author{
Adam A. Bahishti", Abdul Majid \\ Department of Physics, College of Science in Zulfi, Majmaah University, Majmaah 11952, Saudi Arabia \\ *Corresponding author email: a.bahishti@mu.edu.sa \\ Received: 25 September 2017 / Revised: 04 October 2017 / Accepted: 14 October 2017 / Published: 01 November 2017

\begin{abstract}
Many studies on the Photoconductivity of $\mathrm{ZnO}$ have been performed with an indication of reliable optical application due to fast photo response. This paper reports study of intensity dependent photoconductivity in $\mathrm{ZnO}$ nanostructured thin film with a thickness of $800 \mathrm{~nm}$. ZnO nanostructured thin film on ultra clean glass substrate has been deposited using sol-gel spin coating technique. Conductivity at various illumination intensity has been measured using two probe method and found that photoconductivity increases by increasing illumination intensity. Photoconductivity can be utilized in the devices fabrication which are based on the decrease in the resistance of certain materials when they are exposed visible radiation. Photosensitivity and persistent photo conductivity also found to be increasing with illumination intensity. Photo sensitivity enhancement in Nanostructured $\mathrm{ZnO}$ is expected due to its large surface to volume ratio which is fundamentally more suitable for optical devices application. Persistent photoconductivity in the $\mathrm{ZnO}$ nanostructure thin film can be utilize in memory device applications.
\end{abstract}

\section{Introduction}

Photoconductivity is considered as an optical and electrical phenomenon where a material becomes electrically more conductive by absorbing electromagnetic radiation [1], [2]. It is the consequences of carrier excitation due to light absorption and its novelty depends on the light absorption efficiency [3], [4]. The increase in conductivity is due to an increase in the number of mobile charge carriers in the material. Photoconductive materials form the origin of light controlled electrical devices due to current ceases when the illumination is removed. These materials are also used to manufacture detection devices for infrared radiation in military applications such as missiles guidance to heat producing targets. Photoconductivity has broad commercial application in the process of Xeroxography which uses selenium but now relies on photoconductive polymers. Zinc oxide $(\mathrm{ZnO})$ is an important photonic material because of its wide band gap of about to $3.37 \mathrm{eV}$ and large exciton binding energy of $60 \mathrm{meV}$ of excitons at room temperature [5]. Recently, $\mathrm{ZnO}$ attracted a great deal of attention due to its light detection properties with several studies related to photoconductivity [6]-[9]. Our previous study shows that laser light irradiation can produce significant effect on materials which is attributed to the optical absorption [3], [4], [10]-[12] however we didn't made study on Zn based material. There has been a significant rise in the number of scholarly publications addressing $\mathrm{Zn}$ based materials in the last decade indicating significant new interest [13]-[15]. Post-illumination persistence photoconductivity has been reported in $\mathrm{ZnO}$ based UV photodevices by Moore et al [16]. The exploration of photoconductivity in $\mathrm{ZnO}$ nanostructures gained attention due to existence of visible-ultraviolet photo response in $\mathrm{ZnO}$ nanowire. Photoconductivity in various $\mathrm{ZnO}$ nanostructures such as nano needles, nano rods, nano films and nano wires have been considerably investigated by many researchers [6]-[8], [17]-[21] for the UV devices applications and fundamental studies. Hong-Liang Lu et al [22] reported a new type of memory device by utilizing photoconductivity effect. They found that the insulating LAO/STO interface can be converted to its metallic state by UV or visible light

Copyright (C) 2017. The Author(s). Published by AIJR Publisher.

This is an open access article under Creative Commons Attribution-NonCommercial 4.0 International (CC BY-NC 4.0) license, which permits any non-commercial use, distribution, adaptation, and reproduction in any medium, as long as the original work is properly cited. 
Intensity Dependent Photoconductivity in $\mathrm{ZnO}$ Nanostructured Film

illumination. The metallic state kept maintained even after light is off due to Persistent photoconductivity effect. Suhail et al [23] reported fabrication of Fast Response ZnO/porous Silicon UV Photoconductive Detector thin films onto nanospikes silicon layer with various etching time through spray pyrolysis using $0.1 \mathrm{M}$ aqueous solution of Zinc acetate. Jiming Bao et al [8] studied photoconductivity in individual $\mathrm{ZnO}$ nanowires under ultraviolet illumination and they observed that the induced photocurrents persist both in air and in vacuum. Pavel Reyes et al [24] reported a ZnO-based thin film transistor UV photodetector with a back gate configuration. Srivastava et al [25] reported anomalous behaviour of photocurrent in $\mathrm{ZnS}: \mathrm{Mn}$ nanoparticles, where the photocurrent decreases even during steady illumination. Many materials have been studies for designing UV devices based on thin films and nanostructures but could not hold significant interest either due to complexity in design or limit of responsivity in such devices. Within the various studied materials, Zinc oxide drawn broad attention due to its notable features of good UV photoconductivity and established material growth techniques in thin film form or nanostructures.

Literature review shows that intensity dependent photo response study in $\mathrm{ZnO}$ nanoparticles has not been explored yet. Intensity dependent photo response can be utilized in Intensity tuned Intensity sensor device application as well as in memory devices. However, the true measurement of photoconductivity towards the $\mathrm{ZnO}$ nanostructure with change in incident intensity remains unknown for efficient detection. Study of the intensity dependent photoconductivity in $\mathrm{ZnO}$ nanostructured thin films and its result might be promising for optical devices fabrication in future.

\section{Materials and methods}

$\mathrm{ZnO}$ thin film of thickness $800 \mathrm{~nm}$ has been deposited on ultra clean glass substrate using sol-gel spin coating technique. $\mathrm{ZnO}$ solution has been prepared by dissolving diethanolamine, monoethanolamine, sodium dodecyl sulfate and zinc acetate dihydrate in absolute ethanol solution. Film deposition process by sin coating technique has been conducted by spraying Argon gas in two steps. Speed of $500 \mathrm{rpm}$ has been kept for 6 seconds in first step and then speed of $1500 \mathrm{rpm}$ has been used for 20 seconds in second step for final film deposition. Finally, the deposited film has been annealed at $300{ }^{\circ} \mathrm{C}$ for 1 hour for further use. As prepared thin film has been characterized by Scanning Electron Microscope which confirms nanostructure of $\mathrm{ZnO}$ film as shown in Figure 1.

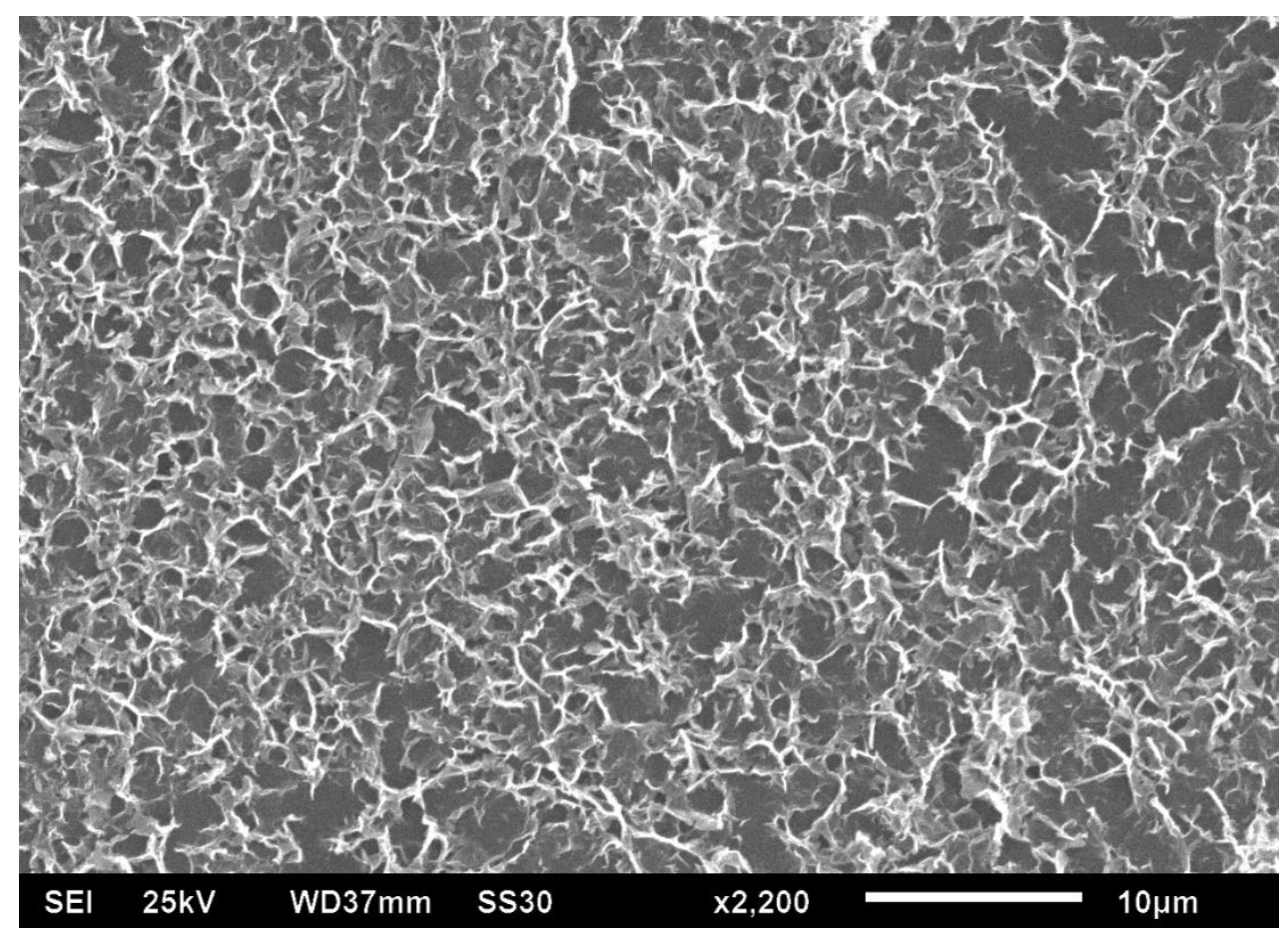

Figure 1: Scanning Electron Microscope image of as deposited $\mathrm{ZnO}$ film. 
Bahishti et al., Adv. Nan. Res.; Vol. 1, Issue 1, pp: 23-30, 2018

For photoconductivity study, electrical contact in prepared thin films has been developed using Silver paste and sample were mounted in a sample holder. Conductivity measurement has been done by standard and most common two-probe method by applying fix biasing potential of $5 \mathrm{~V}$ at room temperature. $200 \mathrm{~W}$ tungsten lamp has been used as illumination source. Light of different intensity has been shined on sample and corresponding illumination current was recorded using I-V measurement unit which basically contains electrometer and stable voltage source. Intensity of used light has been measure using a digital Lux-meter. For the transient photoconductivity measurement, light has been shone on sample and photocurrent of corresponding time has been recorded. When saturation was reached, the light was turned off and the decay in the current with time has been recorded.

\section{Results and Discussion}

Dark current $\left(I_{d c}\right)$ and photocurrent under iIIumination $\left(I_{i l l}\right)$ has been measured and the photocurrent $\left(I_{p h}\right)$ is calculated using relation [26]-

$$
I_{p h}=I_{i l l}-I_{d c}
$$

The conductivity of the film has been calculated using equation

$$
\sigma=\frac{I L}{V A}
$$

where, $I$ is the current measured in ampere, the voltage in volts, $A$ is the cross-sectional area in $\mathrm{cm}^{2}$ and $L$ is the length of the sample in $\mathrm{cm}$.

Dark current of the prepared $\mathrm{ZnO}$ thin film sample has been measured at room temperature $298 \mathrm{~K}$ by applying a constant biasing potential of $5 \mathrm{~V}$ and found $293 \mathrm{pA}$. The photocurrent of the same sample has been measured against different illumination intensity of 150 Lux, 250 Lux, 350 Lux, 450 Lux, 550 Lux and 650 Lux by keeping experimental parameters same. Measured photocurrent has been used to calculate photoconductivity at different illumination intensity using equation 2 and given in Table 1 . The variation in photoconductivity with the illumination intensity has been shown in Figure 2.

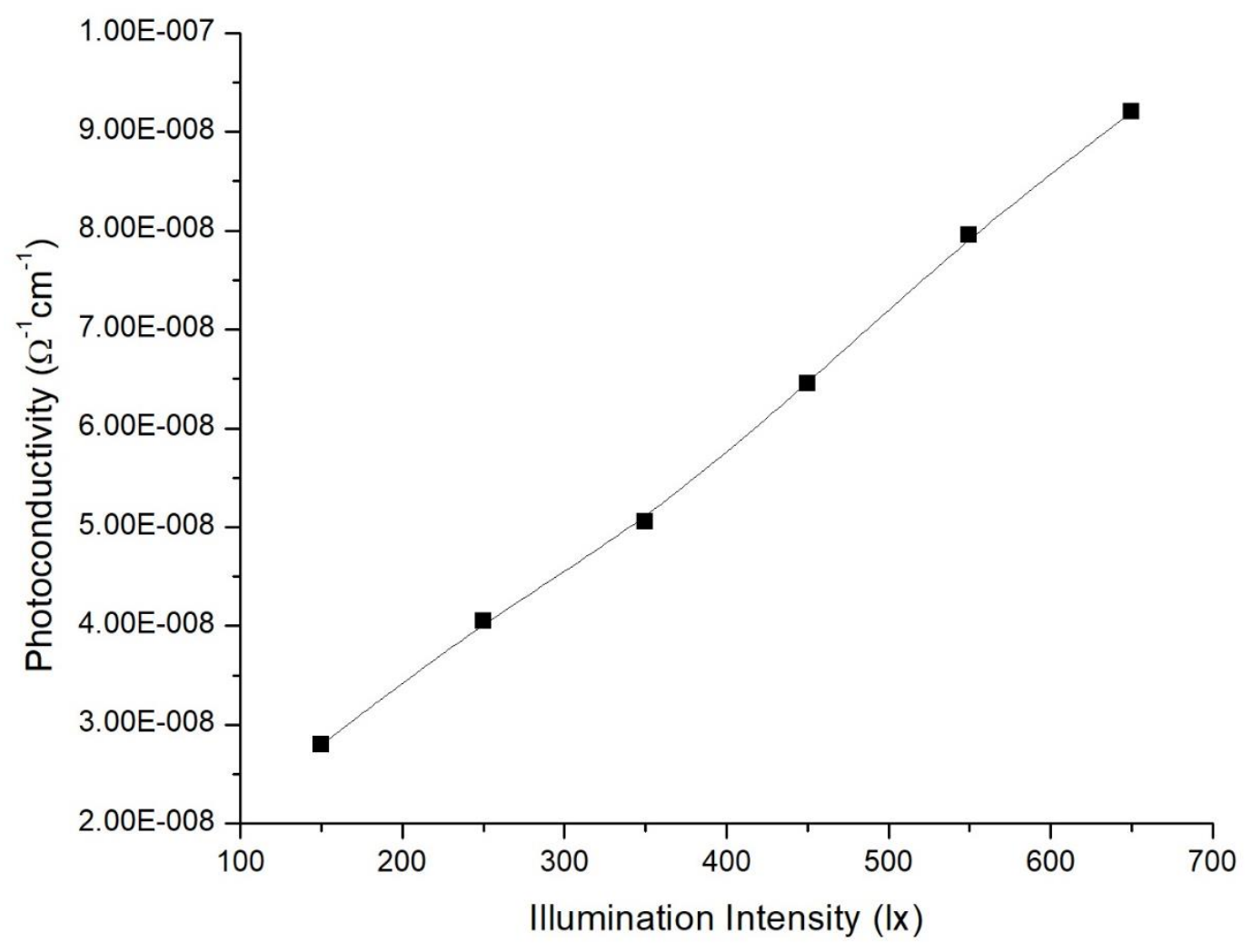

Figure 2: Variation of photoconductivity in $\mathrm{ZnO}$ with illumination intensity. 
Intensity Dependent Photoconductivity in $\mathrm{ZnO}$ Nanostructured Film

Above Figure 2 shows that photoconductivity increases linearly with increasing illumination intensity. Linear dependency of photoconductivity on light intensity indicates that photoconductivity follows a power law with light intensity [2]

$$
\sigma_{p h} \propto F^{\gamma}
$$

Where $\gamma$ represents dependency factor of photoconductivity on illumination intensity. To calculate the power $\gamma$ a curve of $\ln \sigma_{p h}$ versus $\ln F$ has been plotted as shown in Figure 3 whose slope gives the value of $\gamma$ as 0.81 .

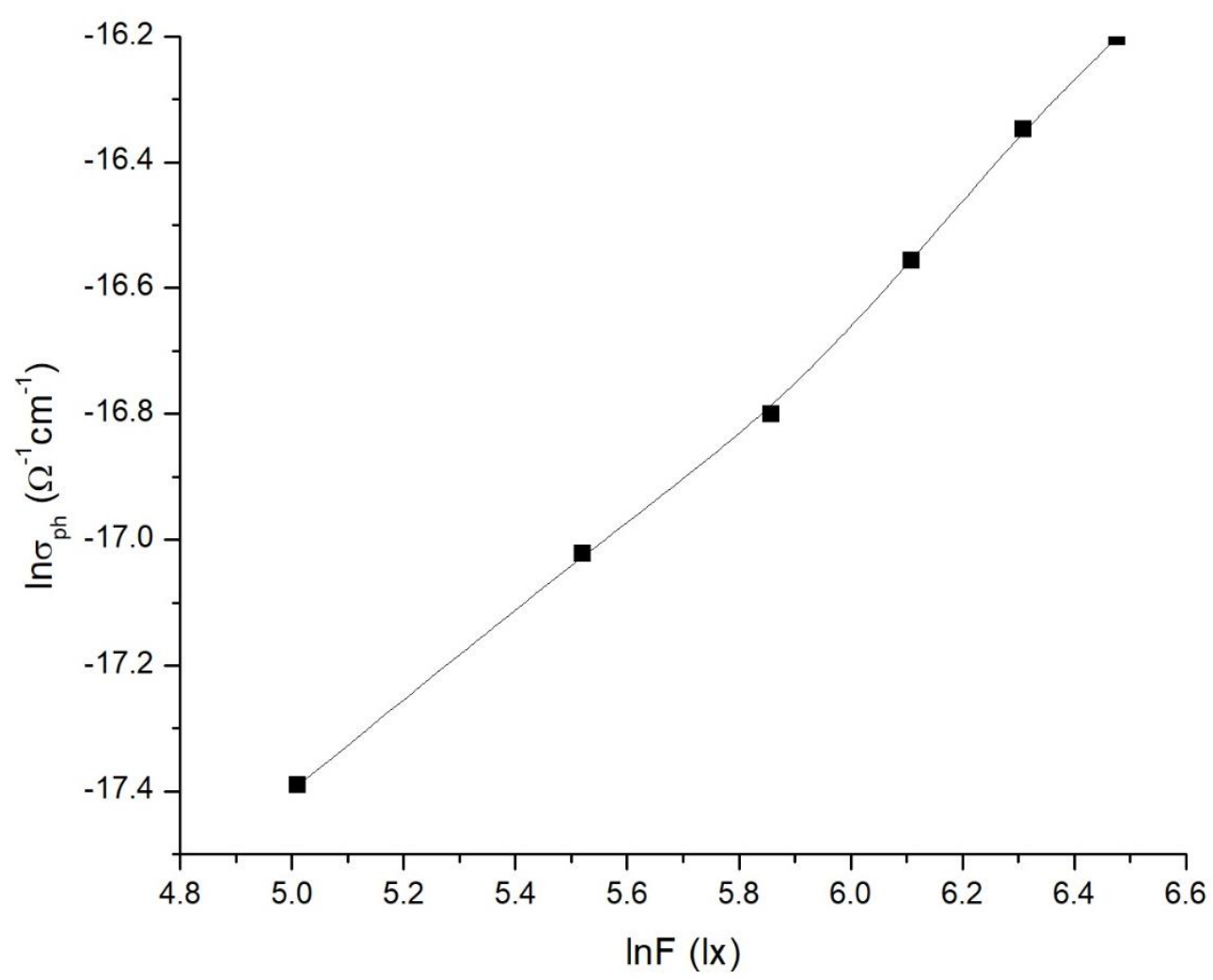

Figure 3: Variation of $\ln \sigma_{p h}$ with $\ln F$ in $\mathrm{ZnO}$ film at room temperature

Table 1: Various conductivity parameters at room temperature

\begin{tabular}{|l|l|l|l|l|l|l|}
\hline \multicolumn{1}{r|}{$\begin{array}{r}\text { Illumination } \\
\text { Intensity }\end{array}$} & $150 l x$ & $250 l x$ & $350 l x$ & $450 l x$ & $550 l x$ & $650 l x$ \\
\hline$\sigma_{\mathrm{ph}}\left(\Omega^{-1} \mathrm{~cm}^{-1}\right)$ & $2.8 \times 10^{-8}$ & $4.05 \times 10^{-8}$ & $5.05 \times 10^{-8}$ & $6.45 \times 10^{-8}$ & $\begin{array}{l}7.95 \times 10^{-} \\
8\end{array}$ & $9.2 \times 10^{-8}$ \\
\hline$\sigma_{\mathrm{ph}} / \sigma_{\mathrm{dc}}$ & 0.1 & 0.14 & 0.17 & 0.22 & 0.27 & 0.32 \\
\hline PPC & 0.038 & 0.044 & 0.051 & 0.055 & 0.101 & 0.140 \\
\hline
\end{tabular}


Bahishti et al., Adv. Nan. Res.; Vol. 1, Issue 1, pp: 23-30, 2018

Photosensitivity of the material is another important parameter to decide its use in photoconductive applications. Photosensitivity is defined as ratio of photoconductivity to the dark conductivity $\left(\sigma_{\mathrm{ph}} / \sigma_{\mathrm{dc}}\right)$. $\sigma_{\mathrm{ph}} / \sigma_{\mathrm{dc}}$ values for different illumination intensity have been calculated at room temperature and given in Table 1. Variation of photosensitivity with illumination intensity is shown in Figure 4. It is observed that photosensitivity increases from 0.1 to 0.32 with increasing illumination intensity from 150 to $700 \mathrm{~lx}$.

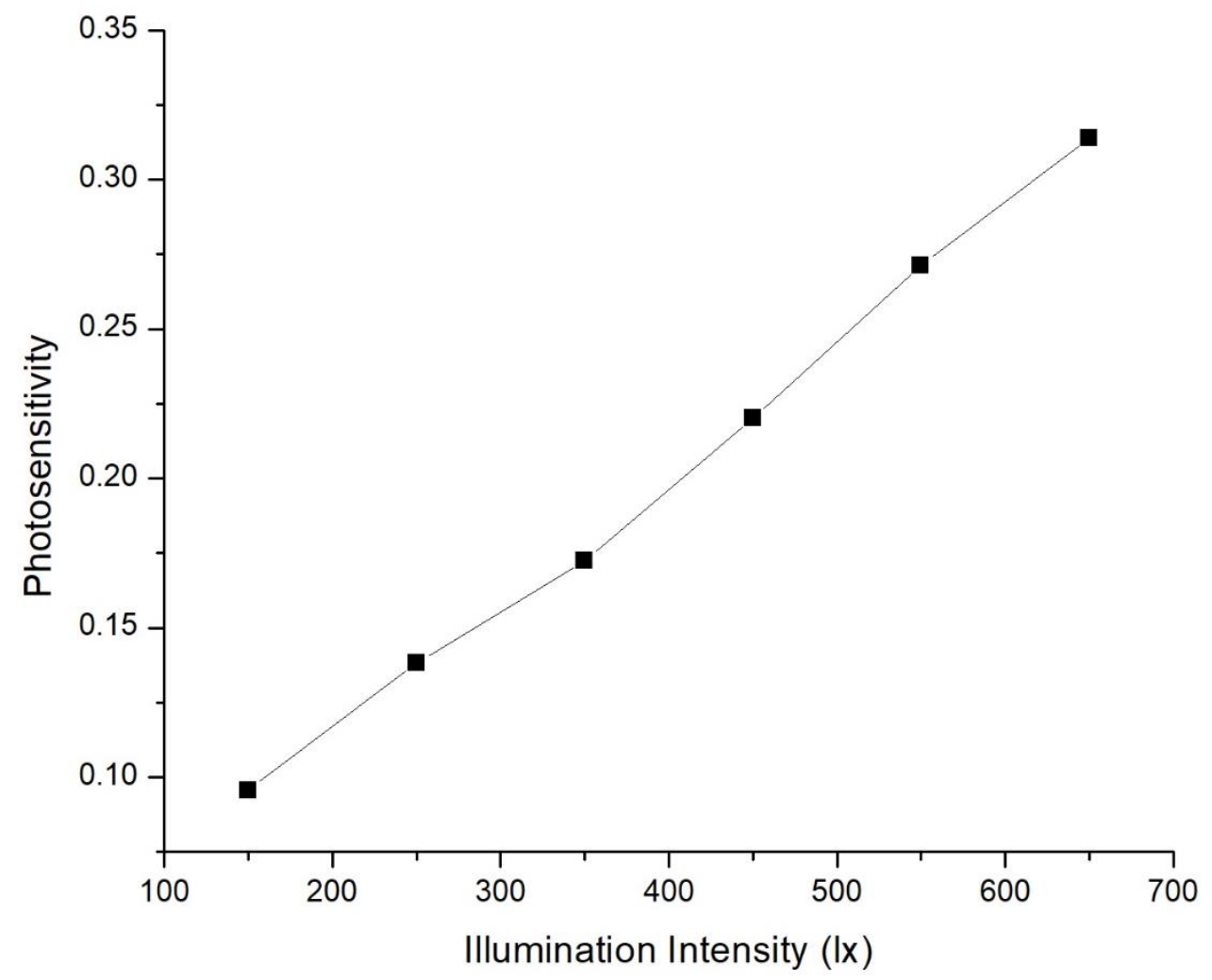

Figure 4: Variation of photosensitivity with illumination intensities in ZnO film at room temperature

Transient photoconductivity at various illumination intensity has been measured at temperature $298 \mathrm{~K}$ on the sample with $5 \mathrm{~V}$ biasing potential. After turning on light rise in current with time has been recorded. After a certain time of illumination, when steady state achieved, light has been turned off and decay of the photocurrent has been measured. The initial dark current has been subtracted to obtain transient photocurrent. The rise and decay of photocurrent with time for all illumination intensities are shown in Figure 5.

It is evident from Figure 5 that the photocurrent initially rises faster then becomes slow and saturated after 250 seconds. After get saturation current the light has been switched off and the photocurrent starts to decay quite fast initially, and then slows down. As time elapses it reaches steady state value in 600 seconds as shown in Figure 5. The decay process took a total of 350 seconds which seems to be composed of two processes, a faster decay at the onset of transient and a slower decay later on. A persistent photocurrent is observed for for all illumination intensities, which did not decay even after a long time-interval. It is believed that such a large decay cannot be due to carriers trapped in the intrinsic defects [27]. It may be due to defects produce in structure on increasing illumination intensity. To compare the persistent photocurrent effect with illumination intensity, we calculate the quantity Persistent Photoconductivity (PPC) [2], [28], [29] as-

$$
\mathrm{PPC}=\left(\sigma_{1}-\sigma_{\mathrm{dc}}\right) / \sigma_{\mathrm{dc}}
$$

where $\sigma_{1}$ the total photo conductivity of the light induced state after the decay of 350 seconds, and $\sigma_{\mathrm{dc}}$ is the dark conductivity of the $\mathrm{ZnO}$ film. 


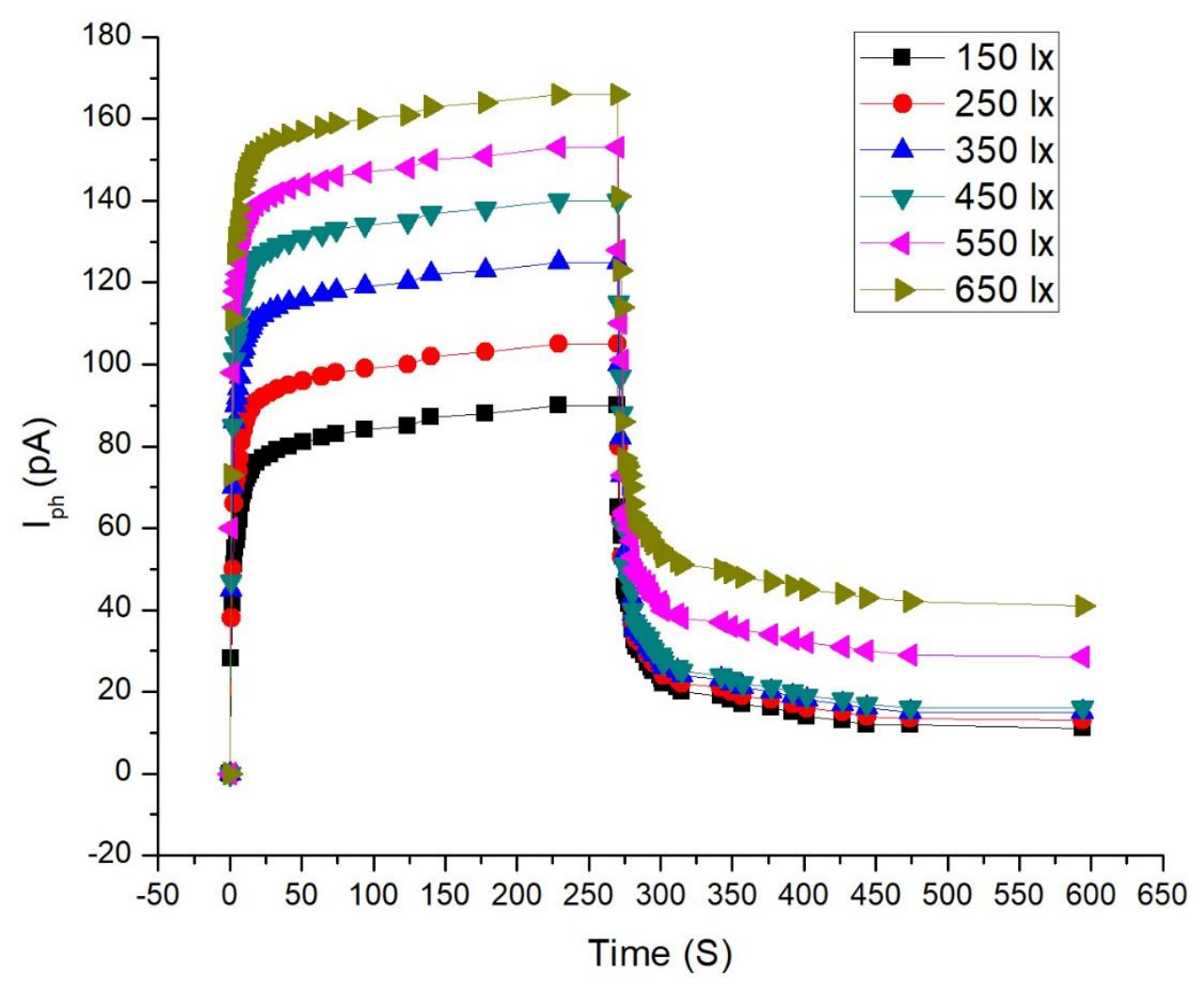

Figure 5: Variation of photocurrent with time in Zno film for various illumination intensities

It is found that PPC increases with increasing illumination intensity as given in Table 1. Ho-Hyun Nahm et al [21] gives a microscopic explanation for persistent photo-conductivity in $\mathrm{ZnO}$ on the basis of bistability of Substitutional hydrogen at oxygen site and suggested that the bistability of the $\mathrm{H}$ donor will provide a new way to consider the physics of hydrogen in oxide materials. James C. Moore et al [16] have reported a phenomenological model of the PPC observed in ZnO based MSM planar photodetector devices through time-resolved surface band bending. Due to migration of photogenerated holes to the surface, surface band bending decreases during light illumination. To recombine with photogenerated holes at the surface, conduction-band electrons must overcome a relatively low energy barrier immediately just after removing illumination; however, the adsorption of oxygen at the surface in the depletion region increases band bending with increasing time, which results in an increased surface energy barrier that slowed down transport of photogenerated electrons.

\section{Conclusion}

Illumination intensity dependent photoconductivity in $\mathrm{ZnO}$ nanostructured film shows a significant increment in the conductivity with the light intensity which may be utilize in designing a light intensity dependent device. Photosensitivity also found to be increasing with illumination intensity which suggest that $\mathrm{ZnO}$ nanostructured film can be useful in fabrication of high sensitive device application to use at higher light intensity. Further, persistent photo conductivity is found to be increases with increasing illumination intensity. A novel application of such intensity dependent ppc is suggested in memory devices, whose "1" state can be triggered by light illumination, maintain due to persistent photo conductivity effect, and returns to " 0 " state through application of a back-gate voltage. Further study is required for better application-based understanding of intensity dependent photoconductivity in $\mathrm{ZnO}$ nanostructured film by considering various optoelectronic parameters. 


\section{Acknowledgment}

Author would like to thank Deanship of Scientific Research, Majmaah University, KSA for providing financial support to carry out this research work.

\section{How to Cite this Article:}

A. A. Bahishti and A. Majid, "Intensity Dependent Photoconductivity in ZnO Nanostructured Film", Advanced Nano Research, vol. 1, no. 1, pp. 23-30, Nov. 2017. doi: 10.21467/anr.1.1.23-30

\section{References}

[1] L. A. DeWerd and P. R. Moran, "Solid-state electrophotography with $\mathrm{Al}_{2} \mathrm{O}_{3}$," Med. Phys., vol. 5, no. 1, pp. 23-26, Jan. 1978.

[2] N. Chaudhary, A. A. Bahishti, and M. Zulfequar, "Photoconductivity of Se85-xTe15Hgx thin films," Phys. B Condens. Matter, vol. 407, no. 12, pp. 2267-2271, Jun. 2012.

[3] A. A. Bahishti, M. A. Majeed Khan, B. S. Patel, F. S. Al-Hazmi, and M. Zulfequar, "Effect of laser irradiation on thermal and optical properties of selenium-tellurium alloy," J. Non. Cryst. Solids, vol. 355, no. 45-47, pp. 2314-2317, Nov. 2009.

[4] A. A. Bahishti, M. A. M. Khan, S. Kumar, M. Husain, and M. Zulfequar, "EFFECT OF LASER IRRADIATION ON THE OPTICAL PROPERTIES OF AMORPHOUS Se 96-x Te 4 Ga x THIN FILMS," Chalcogenide Lett., vol. 4, no. 12, pp. 155-160, 2007.

[5] A. D. A. Buba and J. S. A. Adelabu, "Optical and Electrical Properties of Chemically Deposited ZnO Thin Films," Pacific J. Sci. Technol., vol. 11, no. 2, 2010.

[6] R. Ghosh, B. Mallik, and D. Basak, "Dependence of photoconductivity on the crystallite orientations and porosity of polycrystalline ZnO films," Appl. Phys. A, vol. 81, no. 6, pp. 1281-1284, Nov. 2005.

[7] Z.-M. Liao, Y. Lu, J. Xu, J.-M. Zhang, and D.-P. Yu, "Temperature dependence of photoconductivity and persistent photoconductivity of single ZnO nanowires," Appl. Phys. A, vol. 95, no. 2, pp. 363-366, May 2009.

[8] J. Bao et al., "Photoinduced oxygen release and persistent photoconductivity in ZnO nanowires," Nanoscale Res. Lett., vol. 6, no. 1, p. 404, May 2011.

[9] J. C. Moore, L. R. Covington, R. L. Foster, E. J. Gee, M. R. Jones, and S. A. Morris, "ZnO ultraviolet photodetectors grown via thermal oxidation of Zn-metal on glass and sapphire substrates," 2011, vol. 7940, p. 79401L.

[10] A. A. Bahishti, M. Husain, and M. Zulfequar, "Effects of laser irradiation on optical properties of a-Se ${ }_{100-x} \mathrm{Te}_{x}$ thin films," Radiat. Eff. Defects Solids, vol. 166, no. 7, pp. 529-536, Jul. 2011.

[11] A. A. Bahishti, I. Uddin, M. Zulfequar, T. Alharbi, and T. Alharbi, "Laser Irradiation Effect on the Optical Band Gap of Se96xTe4Hgx Thin Films," J. Mod. Mater., vol. 1, no. 1, pp. 17-23, Jul. 2016.

[12] A. A. Bahishti, I. Uddin, and M. Zulfequar, "Laser Irradiation Effect on the Optical Band Gap of Se-Te-Al Thin Films," Int. Ann. Sci., vol. 1, no. 1, pp. 8-14, Oct. 2016.

[13] C. M. Firdaus, M. S. B. S. Rizam, M. Rusop, and S. R. Hidayah, "Characterization of ZnO and ZnO: TiO2 Thin Films Prepared by Sol-Gel Spray-Spin Coating Technique,” Procedia Eng., vol. 41, pp. 1367-1373, Jan. 2012.

[14] K.-T. Lam, Y.-J. Hsiao, L.-W. Ji, T.-H. Fang, K.-H. Hsiao, and T.-T. Chu, "High-Sensitive Ultraviolet Photodetectors Based on ZnO Nanorods/CdS Heterostructures," Nanoscale Res. Lett., vol. 12, no. 1, p. 31, Dec. 2017.

[15] H. Howari, I. Uddin, and I. Uddin, "Variations in Optical Properties of $\mathrm{ZnS} / \mathrm{Cu} / \mathrm{ZnS}$ Nanostructures Due to Thickness Change of ZnS Cap Layer," J. Mod. Mater., vol. 2, no. 1, pp. 25-30, Oct. 2016.

[16] J. Moore and C. Thompson, "A Phenomenological Model for the Photocurrent Transient Relaxation Observed in ZnO-Based Photodetector Devices," Sensors, vol. 13, no. 8, pp. 9921-9940, Aug. 2013.

[17] P. Irkhin, H. Najafov, and V. Podzorov, "Steady-state photoconductivity and multi-particle interactions in high-mobility organic semiconductors," Sci. Rep., vol. 5, no. 1, p. 15323, Dec. 2015.

[18] R. S. Saxena, R. K. Srivastava, S. K. Mishra, and R. K. Shukla, "Study of Photoconductivity and Photoluminescence in ZnO Microstructures Synthesized by Thermal Decomposition of Zinc Nitrate,” Proc. Natl. Acad. Sci. India Sect. A Phys. Sci., vol. 88, no. 1, pp. 157-162, Mar. 2018.

[19] P. Biswas and P. Banerji, "Varying Photoconductivity of $\mathrm{ZnO}$ as a Function of Annealing Temperature," Springer, Cham, 2014, pp. 819-821.

[20] Y. Takahashi, M. Kanamori, A. Kondoh, H. Minoura, and Y. Ohya, "Photoconductivity of Ultrathin Zinc Oxide Films," Jpn. J. Appl. Phys., vol. 33, no. Part 1, No. 12A, pp. 6611-6615, Dec. 1994.

[21] H.-H. Nahm, C. H. Park, and Y.-S. Kim, "Bistability of Hydrogen in ZnO: Origin of Doping Limit and Persistent Photoconductivity," Sci. Rep., vol. 4, no. 1, p. 4124, May 2015.

[22] H.-L. Lu et al., "Reversible insulator-metal transition of LaAlO3/SrTiO3 interface for nonvolatile memory," Sci. Rep., vol. 3, no. 1, p. 2870 , Dec. 2013.

[23] A. M. Suhail, A. N. Naji, G. S. Muhammed, H. A. Thjeel, and Q. G. Al-Zaidi, "Fast Response ZnO/porous Silicon UV Photoconductive Detector," Int. J. Thin Film Sci. Tec. NSP Nat. Sci. Publ. Cor, vol. 1, no. 1, pp. 35-42, 2012.

[24] P. Ivanoff Reyes, C.-J. Ku, Z. Duan, Y. Xu, E. Garfunkel, and Y. Lu, "Reduction of persistent photoconductivity in ZnO thin film transistor-based UV photodetector," Appl. Phys. Lett., vol. 101, no. 3, p. 31118, Jul. 2012.

[25] S. Srivastava, S. K. Mishra, R. S. Yadav, R. K. Srivastava, A. C. Panday, and S. G. Prakash, "PHOTOCONDUCTIVITY AND DARKCONDUCTIVITY STUDIES OF Mn-DOPED ZnS NANOPARTICLES,” Dig. J. Nanomater. Biostructures, vol. 5, no. 1, pp. $161-167,2010$.

[26] S. K. Tripathi and A. Kumar, "Effect of incorporation of Sb and Ge on the photoconductivity of amorphous thin films of Se80Te20," J. Non. Cryst. Solids, vol. 104, no. 2-3, pp. 229-236, Sep. 1988. 
Intensity Dependent Photoconductivity in $\mathrm{ZnO}$ Nanostructured Film

[27] D. Kumar and S. Kumar, "Composition Dependence of Photoconductivity in Amorphous Thin Films of Se .80-x Te .20 Ge x," Turk J Phys, vol. 29, pp. 91-96, 2005.

[28] R. K. Pal, A. K. Agnihotri, and A. Kumar, "PERSISTENCE OF PHOTOCONDUCTIVITY IN AMORPHOUS Se - Te - Zn SYSTEM," Chalcogenide Lett., vol. 7, no. 6, pp. 357-365, 2010.

[29] R. S. Sharma, D. Kumar, and A. Kumar, “Transient Photoconductivity in Amorphous Se-Ge-Ag System,” Turk J Phys, vol. 30, pp. 47-55, 2006.

Publish your research article in AIJR journals-

$\checkmark$ Online Submission and Tracking

$\checkmark$ Peer-Reviewed

$\checkmark$ Rapid decision

$\checkmark$ Immediate Publication after acceptance

$\checkmark$ Articles freely available online

$\checkmark$ Retain full copyright of your article.

Submit your article at journals.aijr.in
Publish your books with AIJR publisher-

$\checkmark$ Publish with ISBN and DOI.

$\checkmark$ Publish Thesis/Dissertation as Monograph.

$\checkmark$ Publish Book Monograph.

$\checkmark$ Publish Edited Volume/ Book.

$\checkmark$ Publish Conference Proceedings

$\checkmark$ Retain full copyright of your books.

Submit your manuscript at books.aijr.org 